\title{
2. ACHIEVING HARMONY THROUGH MUSIC: A COMPARISON BETWEEN ANCIENT GREEK AND CHINESE THOUGHT
}

Rossella Marisi ${ }^{59}$

\begin{abstract}
Ancient Greek and Chinese philosophers held music as a fundamental component of education and deemed it effective in guiding students at gaining harmony within themselves and with one another. A quality music education was thus considered relevant in the Bildung of individuals, the preservation of the state, and the maintenance of harmony between heaven and earth. This study makes a comparison between the thought of Plato and his Greek predecessors on one side, and the one of Confucianism on the other, identifying fascinating similarities which offer a source of inspiration to modern educators.
\end{abstract}

Key words: Confucius, Li Ji, Plato, Pythagoras, Shiji

\section{Introduction}

What does the term "quality education" mean for us? Modern societies share the view that the education system has to fulfill some strongly related functions: to help individuals to develop their powers and capacities in a harmonious manner, so that each of them can take an effective part in social, economic, and political life (Durkheim, 1956). Indeed, the Report of the International Commission on Education for the Twenty-first Century described education as based upon four pillars: learning to know, learning to do, learning to live together, and learning to be (Report of the International Commission, 1996). The first pillar "acknowledges that learners build their own knowledge daily, combining indigenous and 'external' elements", the second "focuses on the practical application of what is learned", the third "addresses the critical skills for a life (...) where all have equal opportunity to develop themselves", and the last pillar "emphasizes the skills needed for individuals to develop their full potential" (EFA, 2005: 30).

The goals mentioned in the last two pillars, which are common to all disciplines, are of a core importance in both the education of individuals and the building of society. Early Greek and Chinese philosophers shared the same understanding, and combined the aims hinted at the last two pillars under the concept of achieving harmony within oneself, with others, and with the natural world (Di Fabio and Tsuda, 2018). This study focuses in particular on the role ancient Eastern and Western philosophy assigned to music, conceived as a reflection of cosmic harmony, and as a means to harmonize each individual's body and soul and to bring all members of a community in harmony with one another.

\footnotetext{
${ }^{59}$ Assistante PhD., Conservatorio “Lorenzo Perosi”, Campobasso, Italy, email: rossellamarisi@ hotmail.it
} 


\section{Music as cosmic harmony made audible}

The etymology of the English word harmony is the Greek word harmonia, which in turn is related to the term harmòs, meaning "joint": this suggests that harmony signifies converging and combining different elements (Franklin 2002). The term he (meaning harmony) is often present also in the Chinese pre-Qin classics (dated pre-221 BC), alluding to various sounds responding to one another "in a mutually promoting, mutually complementing, and mutually stabilizing way" (Li, 2008: 584). It is interesting to notice that for Shi Bo, a minister who lived at the beginning of the eighth century BC, a harmonious world can only result from different, even antithetic elements coming together to create an integrated whole ( $\mathrm{Li}, 2014)$.

In a similar way, in the Greek world, the pre-Socratic philosopher Heraclitus (c. 535 - c. 475 BC) considered harmony as an ever changing result of the integration of different forces: harmony transpires "through the constant flow of reality, through the transitions from one opposite to another" (Drozdek, 2007: 29). Pythagoras (c. $570-$ c. 495 BC) was the first who conceived the notion of harmony of the spheres, identifying a rational order embedded in the universe, when a harmonious and ordered cosmos originated from the initial chaos (Proust, 2011). The concept of a primordial chaos, termed hundun, was shared also by various Chinese schools during the Eastern Zhou, a period spanning from 770 to $256 \mathrm{BC}(\mathrm{Wu}, 2008)$. Pythagoras and his disciples thought that numbers were the foundation of the universe and all of its manifestations: thus, they believed, discovering the mathematic relationships among objects and events was the means to find out the secret laws of the harmoniously interrelated universe (Doukhan, 2010). The wish to understand and control the laws of the universe is certainly a common theme during the history of mankind: indeed, for centuries philosophers and scientists have studied the cyclical succession of the seasons and the regular movements of the heavenly bodies, often with the aim of identifying the best period for realizing planned agricultural works or ship journeys.

The Athenian philosopher Plato (c. 424 - c. 348 BC) also deemed that the demiurge structured the universe disposing the celestial spheres according to specific mathematical proportions demonstrating order, measure and balance: 1:2, 3:2, 4:3, and 9:8 (Plato, 2019b). Recalling a theory first stated by Pythagoras and then developed by Philolaus (c. $470-$ c. 385 BC), Plato argues that it is not a case that the same proportions constitute the basic musical intervals (respectively the octave, the fifth, the fourth and the second), whose sounds can be produced choosing the appropriate length of a vibrating string (Plato, 2019b). Thus, for the Athenian thinker, as music can be composed organizing harmoniously sounds and silence, in the same way as the cosmos is created by harmoniously organized celestial spheres, music represents a small-scale audible model of the whole universe.

Moreover, the orderly arrangement of the heavenly bodies forms the basis for the universe soul which animates the universe, in the same way as the human 
soul animates the body. This further similarity between man and the universe leads the philosopher to consider man as a microcosm reflecting the image of a macrocosm, the universe (Plato, 2019b): due to this correspondence, music is able to reorder human beings within the cosmic framework. The Pythagoreans also matched lives of men with lives of stars and thought that the former could mirror the serenity of the latter in their spirit. However, if their spirit was upset by a violent passion or an internal psychic conflict, men should find a way to return in harmony with the harmony of the cosmos. Musical harmony mirrors the harmony of the universe, since both celestial bodies and musical intervals are constructed on the same mathematical ratios; therefore, music was deemed to be an effective means to restore the pristine harmony of the faculties of the soul (Guthrie 1987).

\section{Music's impact on body and soul}

In the Laws, Plato explains that the goodness and badness of the soul may be put in relation with pleasure and pain, which are the first sensations experienced by humans (Plato, 2013). These sensations can be felt also listening to music, thanks to the mimetic process it carries out (Valiquette Moreau, 2017). Indeed, the individual's soul absorbs sounds and songs accompanying certain events and actions, such as banquets, funerals, and rites, and when it hears the same sounds again, it re-experiences the feelings it had had previously. In this way sounds, melodies, and rhythms become a representation of actions and can evoke emotions and feelings (Woerther, 2008). The power music has on the individual can therefore be considered due not just to a mere physiological response of the human body or a judgment of pleasantness expressed by the mind, but also to memories and anticipations (Pannese, Rappaz and Grandjean, 2016).

Basing on the impact music has on human body and soul, in the Republic Plato reflects on the different harmoniai, each being founded on a certain scale and other musical characteristics: this complex gives origin to the specific ethical character of the actual songs, and leads the thinker to permit some harmoniai and vice-versa forbid others. The permitted harmoniai are the Dorian and the Phrygian, assuming that listening to songs representing respectively the virtuous qualities of strong and resolute fighters and those of teachers and persuaders will inspire the audience to enact the same behaviours (Plato, 2019a). On the contrary, disharmony and bad rhythm in music are associated with immoral character and let arise the latter in listeners (Plato, 2019a).

Like Plato, Chinese philosophers also indicated that regularity and order in music symbolize the same in Nature. A passage in the Yue Ji (Account on music) ${ }^{60}$ explains: "(The five notes, like) the five colours, form a complete and elegant whole" (Yue Ji, 2019: para. 31). Sharing Plato's view, Chinese thinkers argue that music exerts its effect simultaneously on both the physical body and the mood of human beings, with a mutually reinforcing effect: in this way the appropriate

\footnotetext{
${ }^{60}$ The Yue Ji is part of the $\mathrm{Li} J i$ (Book of rites), which is one of the Five Classics of Confucius, destroyed in 213 $\mathrm{BC}$ and rewritten by Confucius's disciples.
} 
music can raise certain ethical qualities in the listener to a higher degree. The Yue Shu (Treatise on music ${ }^{61}$ points out that vigorous, violent and forceful music makes blood circulation faster, leads people to move their limbs and inspire steadfastness and resoluteness; calm and majestic music makes the public decorous and religious; peaceful and quiet music inspires kindness and empathy in the audience (Kaufmann, 1976). Yet the same text also warns that trivial, dissolute, and rushed music can make the public evil-minded (Kaufmann, 1976). Vice-versa, when appropriate music prevails, it enhances the listeners' virtuous qualities and spiritual power and promotes clear and effective human relations (Wang, 2004).

\section{Music's effects on society}

In ancient Chinese culture, music serves thus to balance and harmonize the individual's character; indeed, thanks to the positive influence music has on him, the individual becomes a self-aware and self-confident junzi (gentleman), harmonizing that which is innate in him and that which is acquired (O'Donnell, 2019). Achieving this goal, the junzi makes his inner state harmonious with his outer behaviour, becoming a role model who can lead and instruct society (Steben, 2012), namely being an agent of sociocultural cohesion and ordering (Hall and Ames, 1987). Therefore, the function of music stretches far beyond the sphere of individual growth (Steben, 2012), acting also to promote balance and harmony in society. In effect, these two goals, which are tied with the notion of cosmic harmony, are always closely connected in Confucian philosophy (Steben 2012). The disciples of Confucius who edited the Yue $\mathrm{Ji}$ expressed the view that if gradually larger groups learn to passionately appreciate music, their interior harmony will reach other individuals and groups, eventually affecting the whole society (Steben 2012). These reflections show that in classical Confucianism music is not simply a social product, but it also leads to sociality (Garrison, 2012).

Greek thinkers too recognized that listening to appropriate music has a central relevance for the whole society. As reported by Plato in the Republic, the musicologist Damon, who lived in the fifth century BC, claimed that music can affect the stability of the state, either positively or negatively (Plato, 2019a). Some scholars argued that this concept arose in a period characterized by both a perceived disorganization and decreased effectiveness of the Athenian democracy and new harmoniai invented and performed in order to entertain the masses (Csapo, 2011).

Plato too was concerned that this kind of musical innovation did not just violate musical rules, but did create the premises for a disregard of authority and even an irreparable collapse of the state: "Lawlessness of this kind (...) sinks bit by bit into peoples' actions and character; it then looms up and infects their business dealings, and goes on to treat legal and social norms with wanton

\footnotetext{
${ }^{61}$ The Yue Shu is part of Sima Qian's Shiji (Records of the Grand Historian), finished around 94 BC.
} 
disregard, until it finally creates total havoc in both the private and public sphere" (D’Angour, 2013: 299).

In fact, the Athenian philosopher deemed that the structure of both the universe and the state is deeply affected by music. The latter can have a negative effect: this occurs when the musical changes lead to transgressions which could even cause the weakening of fundamental political laws (Plato, 2019a). However, if the traditional harmoniai and performance styles remain unchanged, the appropriate social organization will be preserved. Therefore, as expressed in the Laws, Plato believes that it is task and responsibility of the state to provide its citizens with an appropriate education, which makes them eager to understand "how to rule and how to obey", in order to become perfect citizens (Plato, 2013: book 1). Such education should be regulated and managed by specific state boards and should be based on standardized programs on music and gymnastics. These disciplines were usually included in the education practices utilized in Athens already in the sixth century BC, aimed at guiding students to acquire balanced skills and become "fair in mind and body" (Wallace 2015: Appendix 4a at 9).

In Plato's mind, teaching an approved curriculum, steady over the generations, could contribute to the achievement of important goals: i) adherence to the highest standards of quality in education, ii) limited occurrence of harmful innovations, and iii) maintenance of the state's democracy and independence (Basinger, 2016). Focusing on Confucius's Analects (Confucius, 2019), research stressed that the Chinese philosopher expressed a view similar to that of Plato, emphasizing that rites and music accomplish the most desirable goals: they "reaffirm the line of transmission with the founders of civilization and also reharmonize man with the cosmic Powers that gave birth to his existence, dissolving social frictions in the process" (Steben, 2012: 2).

\section{Concluding remarks}

Both Chinese and Greek thinkers share the opinion that a quality music education can guide each individual to achieve harmony within himself, with others, and with the natural world. This broad and rich understanding of quality in music education is certainly appealing also to modern educators.

\section{References}

1. Basinger Dereck Wayne, (2016), Homer's Music through Plato's Ears, College of William and Mary, Williamsburg, VA.

2. Confucius, (2019), The Analects, Chinese Text Project, https://ctext.org/analects (accessed 14.10.2019).

3. Csapo Eric, (2011), The Economics, Poetics, Politics, Metaphysics, and Ethics of 'New Music', in Dimitrios Yatromanolakis (ed.), Music and Cultural Politics in Greek and Chinese Societies: Greek Antiquity, Harvard University Department of the Classics, Cambridge, MA. 
4. D'Angour Armand, (2013), Plato and Play: Taking Education Seriously in Ancient Greece, "American Journal of Play", vol. 5, No. 3, 293-307.

5. Di Fabio Annamaria and Tsuda Akira, (2018), The Psychology of Harmony and Harmonization: Advancing the Perspectives for the Psychology of Sustainability and Sustainable Development, "Sustainability", vol. 10, No. 12, December 2018, 4726.

6. Doukhan Lilianne, (2010), In Tune with God, Autumn House Publishing, Hagerstown, MD.

7. Drozdek Adam, (2007), Greek Philosophers as Theologians: The Divine Arche, Routledge, New York.

8. Durkheim Emile, (1956), Education and Sociology, Free Press, New York.

9. Garrison James, (2012), The Social Value of Ritual and Music in Classical Chinese Thought, "Teorema International Journal of Philosophy", vol. 31, No. 3, 209-222.

10. Guthrie Kenneth Sylvan, (1987), The Pythagorean Sourcebook and Library: An Anthology of Ancient Writings Which Relate to Pythagoras and Pythagorean Philosophy, Phanes Press, Grand Rapids MI.

11. Hall David L. and Ames Roger T., (1987), Thinking Through Confucius, State University of New York Press, Albany, NY.

12. Li Chenyang, (2014), The Confucian Ideal of Harmony, Routledge, New York.

13. Li Chenyang, (2008), The Ideal of Harmony in Ancient Chinese and Greek Philosophy, "Dao", vol. 7, No. 1, 81-98.

14. O'Donnell Patrick S., (2019), A Study Guide for Confucianism, https://www.academia.edu/6597071/Confucianism_a_study_guide (accessed 14.10.2019).

15. Pannese Alessia, Rappaz Marc-André, and Grandjean Didier, (2016), Metaphor and music emotion: Ancient views and future directions, "Consciousness and Cognition", vol. 44, 61-71.

16. Plato, (2013), Laws by Plato, https://www.gutenberg.org/files/1750/1750h/1750-h.htm (accessed 14.10.2019).

17. Plato, (2019a), Plato: Politeia, https://www.ellopos.net/elpenor/greektexts/ancient-greece/plato/plato-politeia.asp (accessed 14.10.2019).

18. Plato, (2019b), Plato's Timaeus, https://www.ellopos.net/elpenor/physis/plato-timaeus/default.asp (accessed 14.10.2019).

19. Proust Dominique, (2011), The Harmony of the Spheres from Pythagoras to Voyager, in Doris Valls-Gabaud and Alexander Boksenberg (eds.), The Role of Astronomy in Society and Culture Proceedings IAU Symposium No. 260, Cambridge University Press, Cambridge, 358-367.

20. Report to UNESCO of the International Commission on Education for the Twenty-first Century, (1996), UNESCO, Paris.

21. Steben Barry Dale, (2012), The Philosophy of Music and Ritual in Pre-Han 
Confucian Thought: Exalting the Power of Music in Human Life, "Asian Cultural Studies", No. 38, 1-26.

22. Valiquette Moreau Nina, (2017), Musical Mimesis and Political Ethos in Plato's Republic, "Political Theory", vol. 45, No. 2, 192-215.

23. Wallace Robert W., (2015), Reconstructing Damon: Music, Wisdom Teaching, and Politics in Perikles' Athens, Oxford University Press, Oxford.

24. Wang Yuhwen, (2004), The Ethical Power of Music: Ancient Greek and Chinese Thoughts, "The Journal of Aesthetic Education", vol. 38, No. 1 (Spring, 2004), 89-104.

25. Woerther Frederique, (2008), Music and the Education of the Soul in Plato and Aristotle: Homoeopathy and the Formation of Character, "The Classical Quarterly”, vol. 58, No. 1,89-103.

26. Wu Zhonxian, (2008), Vital Breath of the Dao: Chinese Shamanic Tiger Qigong, Singing Dragon, London.

27. Yue Ji, (2019), Chinese Text Project, https://ctext.org/liji/yue-ji (accessed 14.10.2019). 